\title{
A rare complication of ESWL: Focal metastatic multiple organ abscesses in a horseshoe kidney
}

\author{
Ugur Kuyumcuoglu ${ }^{1}$, Bilal Eryildirim ${ }^{2}$, Murat Tuncer $^{2}$, Gokhan Faydaci ${ }^{2}$, Tevfik Aktoz ${ }^{1}$, \\ Hakan Akdere ${ }^{1}$, Kemal Sarıca ${ }^{2}$ \\ ${ }^{1}$ Trakya University, Faculty of Medicine, Urology Clinic, Edirne,Turkey; \\ ${ }^{2}$ Lutfi Kirdar Training and Research Hospital Urology Clinic, Istanbul, Turkey.
}

\begin{abstract}
Summary Extracorporeal shock wave lithotripsy (ESWL) is an effective treatment modality in the minimal invasive management of urinary system stone disease. Although the majority of the complications occuring after ESWL are minor ( most common ones are gross haematuria, pain, perinephritic hematoma); bacteriuria may also occur in some cases which sometimes can lead to sepsis and even metastatic abscess formation in a very rare part of the cases treat$e d$. In this rare situation infection agent spreads quickly via hematogenous route and causes abscess formation in different parts of the body. Majority of such cases usually have an underlying systemic disease like diabetes mellitus (DM), malignancy, HIV or steroid use which lead to disruption of immune system functions. Abscess formation following ESWL is extremely rare and usually limited with some case reports published in the literature. Herein, we present a diabetic case with formation of multiple abscess foci in kidney, as well as in lungs and liver following ESWL. The patient was first admitted to our emergency department with high fever and respiratory distress and misdiagnosed as metastatic tumor foci based on radiologic findings. To the best of our knowledge, our case is the first one in the literature in whom simultanous abscess formation in multiple organ systems has been documented following an otherwise uneventful ESWL.
\end{abstract}

KEY WORDS: ESWL (Extracorporeal Shockwave Lithotripsy); Abscess; Complications.

Submitted 11 September 2013; Accepted 31 January 2014

\section{INTRODUCTION}

As a minimal invasive management alternative ESWL is an effective, safe and practicle treatment in the treatment of urinary system stones (1). However, accumulated experience so far has clearly shown that despite its safe nature; some certain complications ( majority of which are minor) may occur following this procedure. In addition to the traumatizing effects of high energy shock waves (HESW) on renal parenchyma: these complications may also originate

No conflict of interest declared. from residual stone fragments and infection after the procedure. The trauma induced by HESW during ESWL may allow spread of the bacteria in urine to the bloodstream resulting in infectious complications like bacteriuria, bacteraemia, urinary tract infection, urosepsis, perinephric abscess formation and even death in rare cases (2). Related with this subject, bacteriemia may occur in $4 \%$ of patients treated with ESWL which constitutes the main underlying risk for the formation of distant organ metastatic abscesses. Last but not least, these infectious complications can cause urosepsis in a rarely encountered manner (3).

Herein we present a diabetic case admitted to our emergency department with high fever and respiratory distress findings. He was first hospitalized with the diagnosis of acute pneumonia and hyperglycemia attack by chest diseases department. Computerized tomography (CT) of thorax and abdomen revealed multiple metastatic masses in lungs, liver and also in parenchyma of horseshoe kidney with an unknown origin.

\section{Case report}

We present a diabetic case admitted to our emergency department with high fever and respiratory distress findings. He was first hospitalized with the diagnosis of acute pneumonia and hyperglycemia attack by chest diseases department. Computerized tomography (CT) of thorax (Figure 1) and abdomen revealed multiple metastatic masses in lungs, liver and also in parenchyma of horseshoe kidney with an unknown origin.

Case report description and figures are in Supplementary materials posted on www.aiua.it

\section{Discussion}

Following its clinical introduction in 1982, ESWL became the preferred treatment modality in the management of urinary calculi with its successful results (4). Accumulated experience in this field of urology did prove the efficacy and safety of this approach based on its minimally invasive nature. However despite its highly successful and safe results, studies did clearly show that this some certain side 
effects can occur following this procedure. Related with this subject the reported complications namely gross haematuria, pain, perinephritic hematoma are generally minor problems which could be treated in a conservative manner in the majority of the cases (5). However, studies again demonstrated that some certain infectious complications such as bacteriuria can also be anticipated after management and it can sometimes lead to sepsis (6). Gram (-) bacteria are the most common agent found after ESWL which could sometimes lead to metastatic abscess formation (5). Related with this subject again metastatic abscess is defined as hematogenous spreading of an infective agent which causes abscess formation in the different parts of the body. Concerning the etiopathogenesis of metastatic abscess formation, patients usually suffer from an underlying systemic disease like diabetes mellitus (DM), malignancy, HIV or steroid use which leads to disruption of immune system functions. The release of bacteria from fragmented stones or infected urine due to tissue injury can also sometimes be responsible for abscess formation. When a focal intraparenchymal abscess occurs, depending on the body defense mechanisms, associated co-morbidities along with the type and efficacy of the treatment, enlargement and rupture of this focal infection may result in spread of infection into the perinephritic area causing perinephritic abscess formation. Although parenchymal and/or perinephritic abscess formation following ESWL has been reported with limited case reports in the literature (7); metastatic abscess formation in other areas of the body following this procedure is an extremely rare complication. While brain abscess formation following ESWL was reported by Zannoud et al. (3); Unal et al reported a giant abscess formation after ESWL which was attached to the abdominal wall enlarging towards the thorax (7).

In our present case, in addition to the multiple abscess foci in the treated kidney, additional metastatic abscess foci have also been detected in other organs including lungs and liver which probably originated from the hematogenous spread of the infection following ESWL. Another interesting aspect of our case is that radiologists misdiagnosed the simultaneous hypodense noduler lesions as metastatic tumors of unknown origin involving lungs, liver, and horseshoekidney. To the best of our knowledge, there is no report in the literature demonstrating the simultaneous abscess formation in multiple organs following ESWL. Li et al. presumed that the predisposing factors for sepsis and abscess formation following ESWL are the presence of stones larger than 2 $\mathrm{cm}$, struvite stones, nephrostomy or stents and lastly obstruction in urinary system (5). Diabetes mellitıus could be a predisposing risk factor for abscess formation in our case Besides, we assume that the patient has not been well evaluated with respect to the presence and degree of urinary system infection before ESWL procedure. In that case the procedure might have resulted in bacteriemia originating from an untreated infection before ESWL. Last but not least, the formation of abscess in right perirenal area following an ESWL procedure for the left kidney stone is also an interesting consideration. This can be attributed again with the horseshoe kidney malformation in our case which may predispose the kidney for such a complication.
Figure 1.

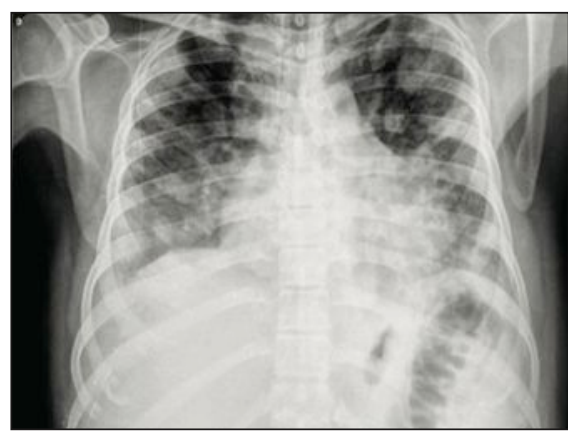

A.

Anterior-posterior chest radiography showing multiple nodular lesions in lungs.

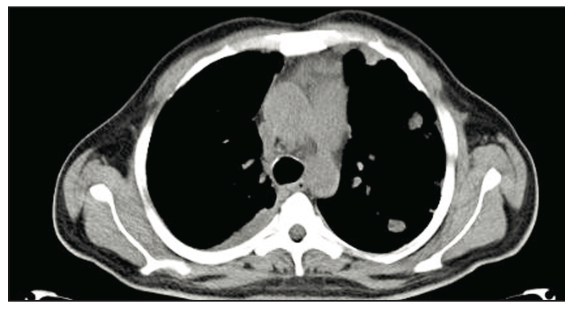

B. Computerized tomography (thorax) showing multiple nodular lesions in lungs.

\section{REFERENCES}

1. Labanaris AP, Kühn R, Schott GE, Zugor V. Perirenal hematomas induced by extracorporeal shock wave lithotripsy (ESWL). Therapeutic management. Scientific World Journal. 2007; 17:1563-66.

2. Skolarikos A, Alivizatos G, de la Rosette J. Extracorporeal shock wave lithotripsy 25 years later: complications and their prevention. Eur Urol. 2006; 50:981-90.

3. Zannoud M, Ghadouane M, Kasmaoui EH, et al. Metastatic cerebral abscess from Klebsiella pneumoniae after extracorporal shock wave lithotripsy for kidney stone (a case report). Ann Urol. 2003; 37:81-84.

4. Chaussy C, Schmiedt E. Shock wave treatment for stones in the upper urinary tract. Urol Clin North Am. 1983; 10:743-50.

5. Li L, ShenN Z, Wang H, eyt al. Investigation of infection risk and the value of urine endotoxin during extracorporeal shock wave lithotripsy. Chin Med J. 2001: 114:510-13.

6. Michaels EK, Fowler JE Jr, Mariano M. Bacteriuria following extracorporeal shock wave lithotripsy of infection Stones. J Urol. 1988; 140:254-56.

7. Unal B, Kara S, Bilgili Y, et al. Giant abdominal wall abscess dissecting into thorax as a complication of ESWL. Urology. 2005; 65:389.

\section{Correspondence}

Ugur Kuyumcuoglu, MD, Professor - kuyumcuugur@yahoo.com

Bilal Eryildirim, MD, Associate Professor - bilaleryildirim@yahoo.com

Murat Tuncer, MD (Corresponding Author) - murattuncer77@hotmail.com

Gokhan Faydaci, MD - faydacig@yahoo.com

Tevfik Aktoz, MD, Associate Professor - taktoz01@yahoo.com

Hakan Akdere, Assistant Professor - hakdere@yahoo.com

Kemal Sarica, MD, Professor - saricakemal@gmail.com

Altunizade mah. Atif bey sok.Gokdeniz sitesi E blok D:20 Kosuyolu, Istanbul, Turkey 